\title{
Contrasting Short- and Long-Term Projections of the Hydrological Cycle in the Southern Extratropics
}

\author{
YUTIAN WU \\ Department of Earth, Atmospheric, and Planetary Sciences, Purdue University, West Lafayette, Indiana \\ LORENZO M. POLVANI \\ Department of Applied Physics and Applied Mathematics, and Department of Earth and Environmental Sciences, \\ Columbia University, New York, New York
}

(Manuscript received 13 January 2015, in final form 26 March 2015)

\begin{abstract}
Analysis of model output from phase 5 of the Coupled Model Intercomparison Project (CMIP5) reveals that, in the zonal mean, the near-term projections of summertime changes of precipitation in the Southern Hemisphere (SH) subtropics are very widely scattered among the models. As a consequence, over the next 50 years, the CMIP5 multimodel mean projects no statistically significant trends in the SH subtropics in summer. This appears to be at odds with the widely reported, and robust, poleward expansion of the subtropical dry zones by the end of the twenty-first century.

This discrepancy between the shorter- and longer-term projections in SH summer, as shown here, rests in the recovery of the ozone hole in the coming decades, as a consequence of the Montreal Protocol. This is explicitly demonstrated by analyzing model experiments with the Whole Atmosphere Community Climate Model, version 4 (WACCM4), a high-top model with interactive stratospheric chemistry, and coupled to land, ocean, and sea ice components. Contrasting WACCM4 integrations of the representative concentration pathway 4.5 with and without trends in surface concentrations of ozone-depleting substances allows for demonstrating that stratospheric ozone recovery will largely offset the induced "wet gets wetter and dry gets drier" projections and the accompanying poleward expansion of the subtropical dry zone in the SH. The lack of near-term statistically significant zonal-mean changes in the SH hydrological cycle during summer is of obvious practical importance for many parts of the world, and it might also have implications for the Southern Ocean and the Antarctic continent.
\end{abstract}

\section{Introduction}

As anthropogenic greenhouse gases (GHG) continue to rise, the hydrological cycle of the earth is expected to change. Held and Soden (2006) originally proposed the "wet gets wetter and dry gets drier" paradigm, which consists of a local intensification of the hydrological cycle accompanying global warming. Subsequent work by Seager et al. $(2007,2010)$ has emphasized that future changes of the hydrological cycle will also be affected by changes in the circulation, notably the poleward expansion of the subtropical dry zones (Lu et al. 2007) and

Corresponding author address: Yutian $\mathrm{Wu}$, Department of Earth, Atmospheric, and Planetary Sciences, Purdue University, 550 Stadium Mall Drive, West Lafayette, IN 47907.

E-mail:wu640@purdue.edu the poleward shift of the midlatitude storm tracks (Yin 2005).

More recently, Scheff and Frierson (2012a) carefully investigated linear trends in precipitation-over the period 1980-2099 - as projected by the models participating in phase 5 of the Coupled Model Intercomparison Project (CMIP5) under representative concentration pathway (RCP) 8.5, the future scenario with greatest emission of greenhouse gases. They found that robust future precipitation declines are located, primarily, poleward of the subtropical minimum of the present-day precipitation climatology. This indicates a poleward expansion of the subtropical dry zones, which they found to be robust in the Southern Hemisphere over the entire seasonal cycle, confirming their earlier findings with the CMIP3 models, where they concluded that changes in extratropical precipitation, by the end of the 
twenty-first century, can be characterized as "mostly midlatitude shifts" (Scheff and Frierson 2012b).

In this paper, we turn our attention to shorter-term projections and focus on zonal-mean hydrological cycle changes in Southern Hemisphere ( $\mathrm{SH}$ ) summer in the next 50 years. In contrast to what has been reported in Scheff and Frierson (2012a), we show that in the coming half century, the zonal-mean projection of the precipitation changes in austral summer is not a poleward shift, as the CMIP5 models show no statistically significant shift in the $\mathrm{SH}$ in that season. Needless to say, the projection of such nonexistent trends over a period lasting several decades into the future is of major practical importance.

To elucidate this lack of zonal-mean trends in the coming decades, we perform modeling experiments of future projections with ozone-depleting substances held fixed at current levels. Using a stratosphere-resolving, chemistry-coupled climate model, we demonstrate that the lack of near-term changes in the $\mathrm{SH}$ hydrological cycle is a clear consequence of the Montreal Protocol, which is expected to cause a substantial decrease in ozone-depleting substances and to result in the closing of the ozone hole in the coming decades.

Our results build on the findings of a number of previous studies (Perlwitz et al. 2008; Son et al. 2009; Polvani et al. 2011; McLandress et al. 2011; Arblaster et al. 2011; Barnes et al. 2014) that have documented that the circulation changes induced by the closing of the ozone hole will largely cancel the effects of increasing greenhouse gases in coming decades. None of these previous studies, however, was specifically focused on the hydrological cycle itself. We here construct a careful budget of the water cycle for the SH and show that the effect of the Montreal Protocol-via the recovery of the ozone hole-is largely dynamical in character, rather than related to thermodynamics.

This paper is organized as follows. In section 2 we describe the climate models and the numerical experiments used in this study. In section 3 we analyze the projections of hydrological cycle changes in both the CMIP5 archive and experiments with and without ozone recovery. The underlying mechanisms are also discussed in section 3. A discussion in section 4 concludes the paper.

\section{Methods}

\section{a. The CMIP5 model output}

We start by contrasting the long- and short-term projections of the CMIP5 models (Taylor et al. 2012). We analyze the future RCP4.5 and RCP8.5 scenario integrations (Meinshausen et al. 2011), where the total GHG radiative forcing reaches 4.5 and $8.5 \mathrm{~W} \mathrm{~m}^{-2}$, respectively, at the end of the twenty-first century, as well as historical integrations. All 24 CMIP5 models with available monthly output of precipitation $(P)$ and evaporation $(E)$ are used here: they are listed in Table 1. All of them are atmosphere-ocean coupled models; however, they comprise a mix of well-resolved and poorly resolved stratosphere components (CharltonPerez et al. 2013). Also, the ozone concentrations in these models are specified in different ways: some of the models have interactive chemistry, while the majority simply read in the ozone concentrations from precomputed values (see Eyring et al. 2013 for more details).

While the CMIP5 integrations provide the latest and, presumably, most accurate version of future projections of climate change in the presence of all known climate forcings, any direct attribution of the projected changes to specific forcings is often difficult, especially when the climate impacts of some of the forcings are of comparable magnitude but opposite in sign. To understand the causes and mechanisms underlying climate projections, it is often easier to use a single model in which individual forcings can be turned on and off, rendering the attribution exercise relatively straightforward.

\section{b. The WACCM4 experiments}

For the task of attribution, therefore, we use a specific model in which we specify single-forcing changes. These were performed with the high-top configuration of the Community Earth System Model, version 1 \{Whole Atmosphere Community Climate Model, version 4 [CESM1(WACCM4)]\}. WACCM4 is a stratosphereresolving atmospheric model coupled to fully interactive stratospheric chemistry, land, ocean, and sea ice components. WACCM4 is one of the models that participated in the CMIP5 exercise, and the "historical" CMIP5 simulations with WACCM4 have been documented in detail in Marsh et al. (2013), which also contains a full description of that model.

In this paper we analyze two sets of WACCM4 integrations. The first set is an ensemble of three RCP4.5 model runs, performed followed the standard CMIP5 specifications for the RCP4.5 pathway, between 2001 and 2065. The second set consists of three integrations identical to those in the first set in every respect, except for the surface concentrations of ozone-depleting substances (ODS): the latter are held fixed at year 2000 values. We refer to these two three-member ensembles as two "experiments."

In the first experiment, labeled simply "RCP4.5," stratospheric ozone over the Antarctic polar cap is fully 
TABLE 1. The 24 CMIP5 models used in this study with information on host institute and atmospheric model resolution (L refers to number of vertical levels, $\mathrm{T}$ to triangular truncation, and $\mathrm{C}$ to cubed sphere).

\begin{tabular}{|c|c|c|}
\hline Institute & Model name & $\begin{array}{l}\text { Atmospheric resolution } \\
\quad(\text { lon } \times \text { lat }) \text { level }\end{array}$ \\
\hline \multirow{2}{*}{$\begin{array}{l}\text { Commonwealth Scientific and Industrial Research Organisation (CSIRO), } \\
\text { Australia, and Bureau of Meteorology (BoM), Australia }\end{array}$} & 1. ACCESS1.0 & N96 $\left(1.875^{\circ} \times 1.25^{\circ}\right) \mathrm{L} 38$ \\
\hline & 2. ACCESS1.3 & N96 L38 \\
\hline Beijing Climate Center, China Meteorological Administration & 3. BCC-CSM1.1 & $\mathrm{T} 42\left(2.8125^{\circ} \times 2.8125^{\circ}\right) \mathrm{L} 26$ \\
\hline Canadian Centre for Climate Modelling and Analysis & 4. CanESM2 & $\mathrm{T} 63\left(1.875^{\circ} \times 1.875^{\circ}\right) \mathrm{L} 35$ \\
\hline National Center for Atmospheric Research (NCAR) & 5. CCSM4 & $288 \times 200\left(1.25^{\circ} \times 0.9^{\circ}\right) \mathrm{L} 26$ \\
\hline $\begin{array}{l}\text { Centre National de Recherches Météorologiques/Centre Européen de } \\
\text { Recherche et de Formation Avancée en Calcul Scientifique }\end{array}$ & 6. CNRM-CM5 & $\mathrm{T} 127\left(1.4^{\circ} \times 1.4^{\circ}\right) \mathrm{L} 31$ \\
\hline $\begin{array}{l}\text { Commonwealth Scientific and Industrial Research Organisation in } \\
\text { collaboration with the Queensland Climate Change Centre of Excellence }\end{array}$ & 7. CSIRO Mk3.6.0 & T63 L18 \\
\hline First Institute of Oceanography, State Oceanic Administration, China & 8. FIO-ESM & T42 L26 \\
\hline \multirow[t]{3}{*}{ Geophysical Fluid Dynamics Laboratory (NOAA GFDL) } & 9. GFDL CM3 & $\mathrm{C} 48\left(2.5^{\circ} \times 2.0^{\circ}\right) \mathrm{L} 48$ \\
\hline & 10. GFDL-ESM2G & $144 \times 90\left(2.5^{\circ} \times 2.0^{\circ}\right) \mathrm{L} 24$ \\
\hline & 11. GFDL-ESM2M & $1.44 \times 90 \mathrm{~L} 24$ \\
\hline NASA Goddard Institute for Space Studies (GISS) & 12. GISS-E2-R & $144 \times 90 \mathrm{~L} 40$ \\
\hline Met Office Hadley Centre (HadGEM2-ES contributed by Instituto & 13. HadGEM2-CC & $192 \times 144\left(1.25^{\circ} \times 1.875^{\circ}\right) \mathrm{L} 60$ \\
\hline Nacional de Pesquisas Espaciais) & 14. HadGEM2-ES & N96 L38 \\
\hline Institute of Numerical Mathematics & 15. INM-CM4.0 & $180 \times 120\left(2.0^{\circ} \times 1.5^{\circ}\right) \mathrm{L} 21$ \\
\hline \multirow[t]{3}{*}{ L'Institut Pierre-Simon Laplace (IPSL) } & 16. IPSL-CM5A-LR & $96 \times 96\left(3.75^{\circ} \times 1.875^{\circ}\right) \mathrm{L} 39$ \\
\hline & 17. IPSL-CM5A-MR & $144 \times 143\left(2.5^{\circ} \times 1.25^{\circ}\right) \mathrm{L} 39$ \\
\hline & 18. IPSL-CM5B-LR & $96 \times 96$ L39 \\
\hline \multirow{3}{*}{$\begin{array}{l}\text { Japan Agency for Marine-Earth Science and Technology, Atmosphere } \\
\text { and Ocean Research Institute (University of Tokyo), and National } \\
\text { Institute for Environmental Studies }\end{array}$} & 19. MIROC-ESM & T42 L80 \\
\hline & 20. MIROC-ESM-CHEM & T42 L80 \\
\hline & 21. MIROC5 & $\mathrm{T} 85\left(1.41^{\circ} \times 1.41^{\circ}\right) \mathrm{L} 40$ \\
\hline Max Planck Institute for Meteorology (MPI-M) & 22. MPI-ESM-LR & T63 L47 \\
\hline Meteorological Research Institute & 23. MRI-CGCM3 & $\mathrm{T} 159\left(1.125^{\circ} \times 1.125^{\circ}\right) \mathrm{L} 48$ \\
\hline Norwegian Climate Centre & 24. NorESM1-M & $144 \times 96\left(2.5^{\circ} \times 1.875^{\circ}\right) \mathrm{L} 26$ \\
\hline
\end{tabular}

recovered by 2065 as one can see, for instance, in Fig. 1a of Smith et al. (2012), where the same runs were analyzed. In the second experiment, ozone concentrations at 2065 are nearly identical to those in the year 2000 . Since increasing greenhouse gases are the major forcing in this second experiment, we label it "GHG $\uparrow . "$ In many figures below, we also plot the difference between the two experiments: this is labeled "ODS $\downarrow$," as ODS are the only forcing that has been changed between the two experiments. Note that while stratospheric ozone is the primary driver of the circulation changes seen in the difference plots, ODS $\downarrow$ is the proper way to label the difference, not "ozone $\uparrow$, , since ozone is interactively computed in WACCM4: surface ODS are the external forcing. Moreover, ODS are the substances actually regulated by the Montreal Protocol, not ozone itself.

Last, for the sake of completeness, a couple of technical notes: 1) the domain of interest here is the $\mathrm{SH}$, between $70^{\circ}$ and $30^{\circ} \mathrm{S} ; 2$ ) for all variables, statistical significance is evaluated via a simple Student's $t$ test, using the $90 \%$ confidence interval; and 3 ) in order to accurately calculate latitudinal shifts of zonal-mean profiles, climate variables are first interpolated onto a $0.1^{\circ}$ grid using a cubic spline interpolation.

\section{Results}

\section{a. CMIP5 hydrological cycle projections}

We start by reproducing the results of Scheff and Frierson (2012a) and, in Fig. 1a, show the future projection of $P$ in an ensemble of CMIP5 models in the RCP8.5 scenario in austral summer during 2001-99 (red line). The curves here are calculated as the sum of the recent climatology (defined as the 1981-2000 average) plus the linear trends in the future simulations from 2001 to 2099. Compared to the climatology (thin black line), the future projection of $P$ is well separated. Note also that the projection is robust across all latitudes at the $90 \%$ level, with a significant wetting trend at mid- to high latitudes (poleward of $50^{\circ} \mathrm{S}$ ) and a drying trend poleward of the subtropical minimum $\left(50^{\circ}-40^{\circ} \mathrm{S}\right)$. The precipitation decline poleward of subtropical minimum (roughly between $37^{\circ}$ and $47^{\circ} \mathrm{S}$ ) results, therefore, in a polweward shift, as reported by Scheff and Frierson (2012a,b).

The point of this paper, however, is that this shift disappears when one considers shorter-term projections. Consider, in particular, the projection for the shorter period 2001-65: it is shown in Fig. 1b for same 
(a) P CMIP5: RCP8.5 2001-2099

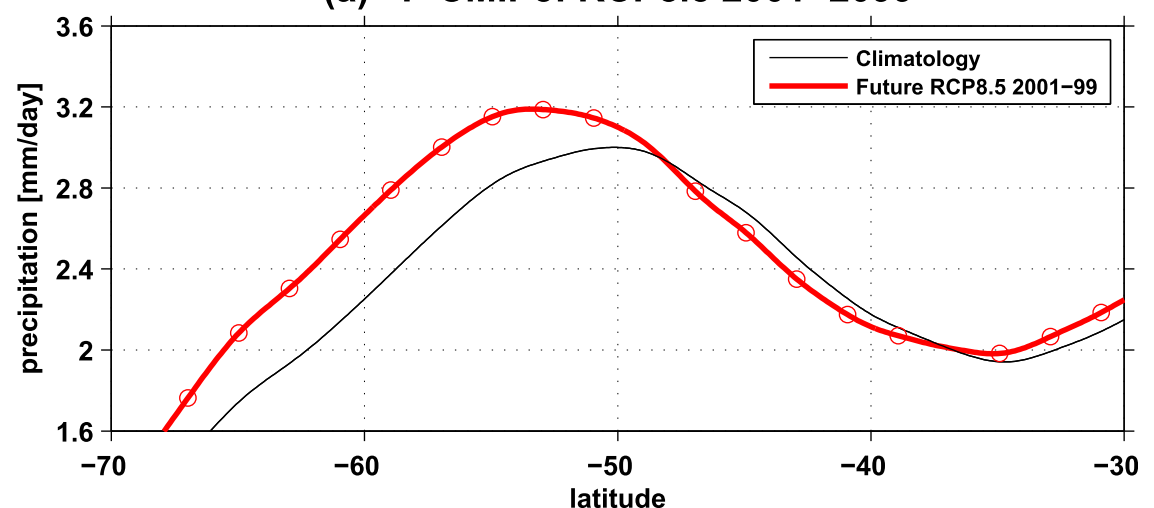

(b) P CMIP5: RCP8.5 2001-2065

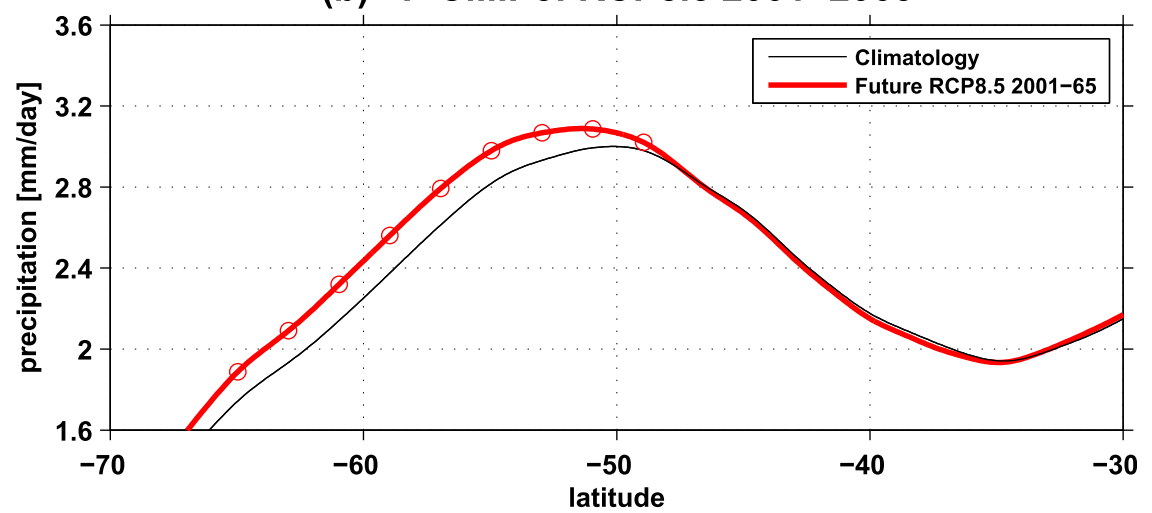

(c) P CMIP5: RCP4.5 2001-2065

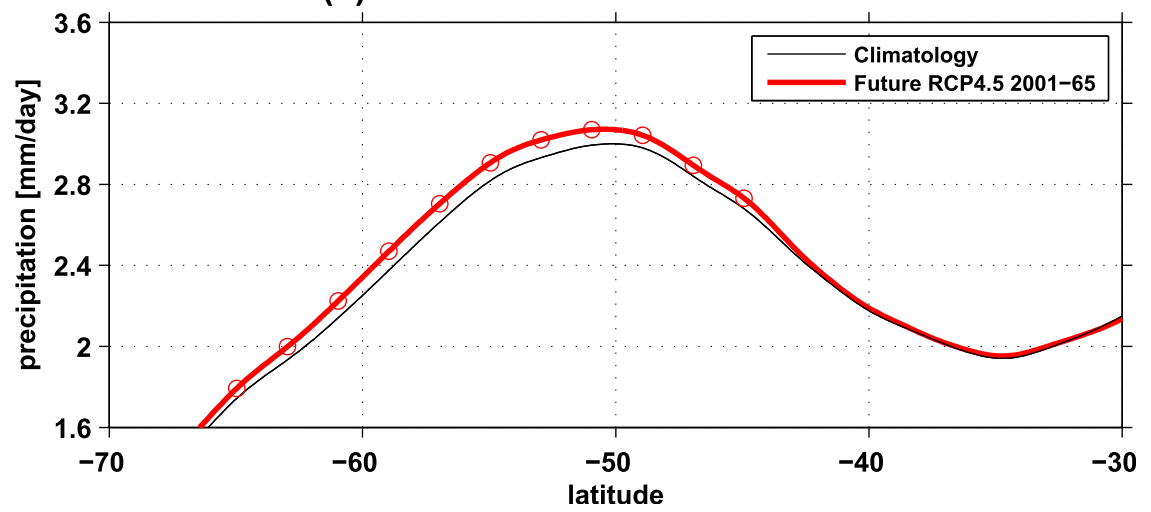

FIG. 1. The future projection of $P$ in austral summer (DJF) for CMIP5 (a) RCP8.5 during 2001-99, (b) RCP8.5 during 2001-65, and (c) RCP4.5 during 2001-65. The climatology, plotted in black, is the CMIP5 multimodel average of 1981-2000 from the historical runs; the future projection in (a), plotted in thick red, is the sum of the climatology and the linear response from 2001 to 2099 in the RCP8.5 scenario, similarly for (b) and (c). Statistically significant responses at the $90 \%$ level are circled.

CMIP5 model simulations. Despite the statistically significant wetting trend at mid- to high latitudes, the drying trend in the subtropical region (between $50^{\circ}$ and $30^{\circ} \mathrm{S}$ ) is no longer robust among CMIP5 models. A similarly insignificant projection is found for the RCP4.5 scenario (shown in Fig. 1c). The agreement between the two scenarios is not surprising, since the forcings are not very different by the year 2065 .

Since the global distribution of precipitation minus evaporation $(P-E)$ better captures the entire hydrological cycle, we show in Fig. 2a the future projection of $P-E$ under RCP8.5 during 2001-99, again in the 
(a) P-E CMIP5: RCP8.5 2001-2099

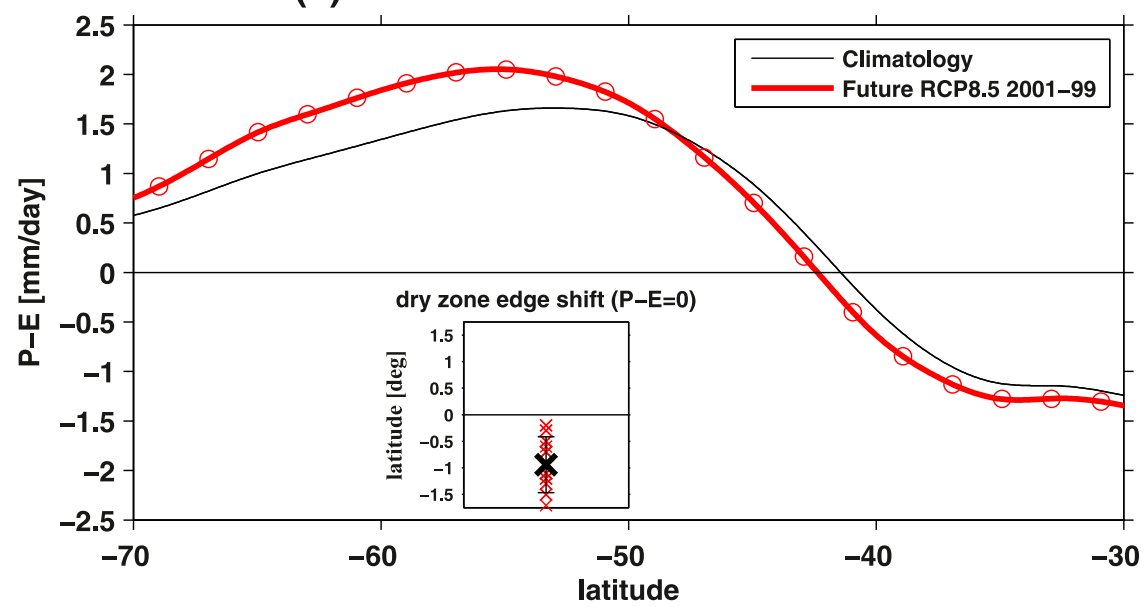

(b) P-E CMIP5: RCP8.5 2001-2065

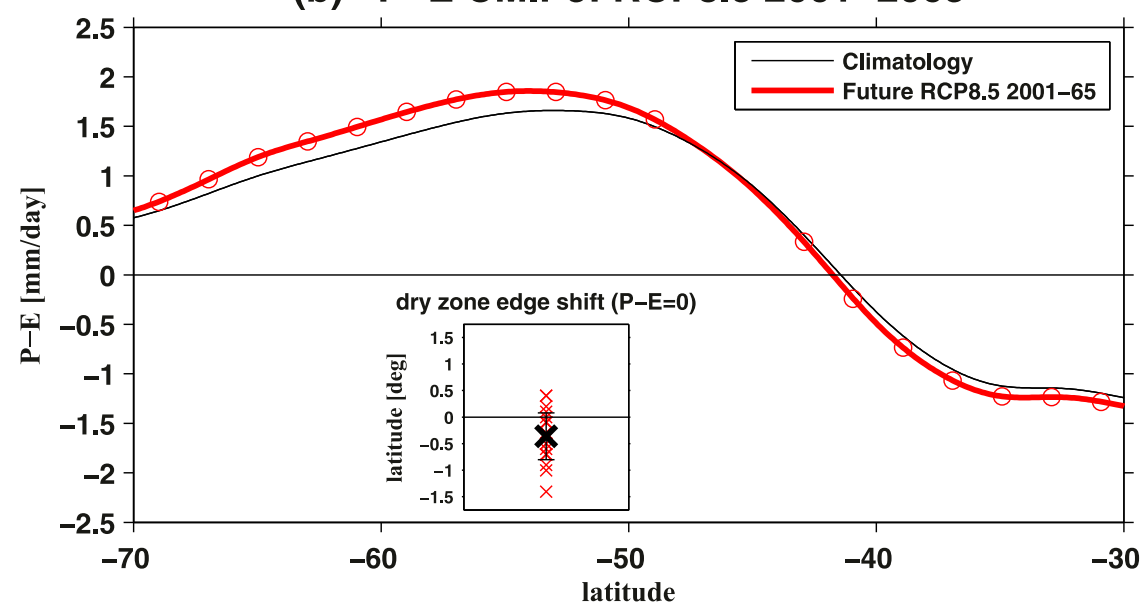

(c) P-E CMIP5: RCP4.5 2001-2065

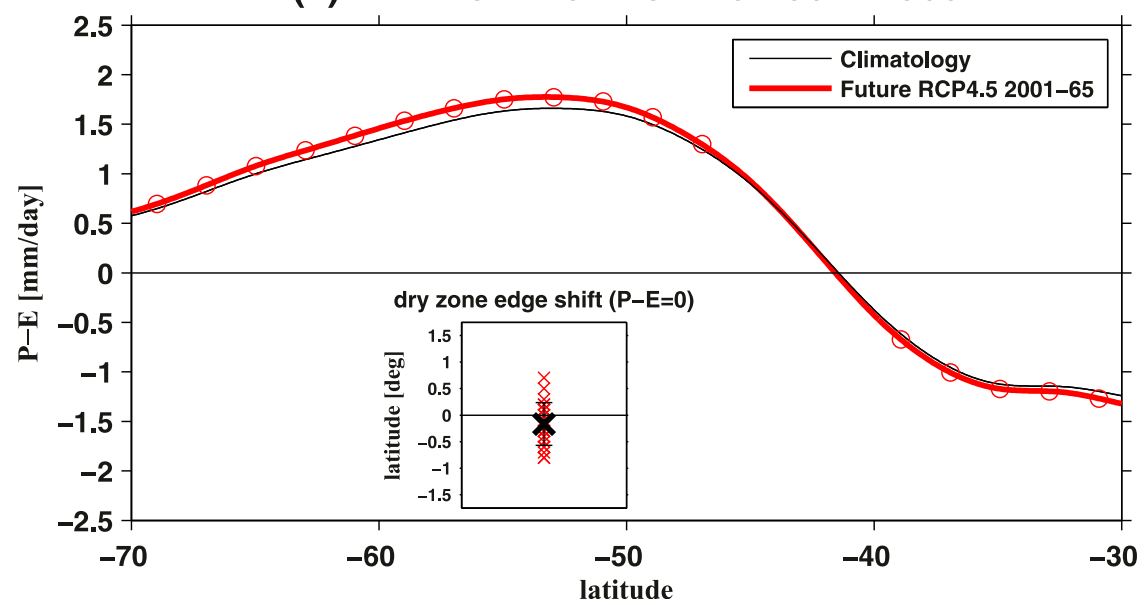

FIG. 2. As in Fig. 1, but for $P-E$. In the inset plot, the latitudinal shift of the subtropical dry zone edge, which is measured by the zero crossing of $P-E$, is plotted with a red cross for each model and the thick black cross is for the multimodel average. The bar shows one standard deviation of the multimodel results. 
CMIP5 models. As for $P$ alone, the future projection of $P-E$ is also well separated from its climatology by the end of the century, with a large wetting trend poleward of $50^{\circ} \mathrm{S}$ and a drying trend equatorward of about $50^{\circ} \mathrm{S}$. One difference between Fig. 1a and Fig. 2a is seen around $30^{\circ} \mathrm{S}$, where the $E$ increases more than $P$.

The actual value of the latitudinal shift of the subtropical dry zone edge for each model-that is, the zero crossing of $P-E$-is shown in the inset plot of Fig. 2a. As one can see, the subtropical dry zone edge shifts poleward by about $1^{\circ}$ latitude in multimodel mean, and this poleward expansion is highly robust among the CMIP5 models: not a single model shows an equatorward shift.

For the shorter period 2001-65, Fig. 2b shows the $P-E$ projections for the same simulations. Comparing these to Fig. $1 \mathrm{~b}$, we note that the $P-E$ reduction is statistically significant in most of the subtropical region: this is due to the robust increase of $E$ there. More importantly, in contrast to Fig. 2a, the latitudinal shift of the subtropical dry zone edge is no longer statistically significant and is more widely spread across the CMIP5 models. Furthermore, a latitudinal shift of the subtropical dry zone edge is also absent in the RCP4.5 simulations, shown in Fig. 2c, over the period of ozone recovery. Similar findings of near-zero trends in the SH summer in the coming decades have been reported in Barnes et al. (2014). The question at this point becomes, why is the shift missing in the short-term projections?

\section{b. WACCM4 hydrological cycle projections: The role of $O D S$}

To attribute the missing shift of the SH subtropical dry zone edge in the coming decades directly to the Montreal Protocol, which controls ODS, we next turn to the single-forcing experiments with WACCM4. Consider first the zonal-mean $P-E$ linear trend over the period 2001-65 from the RCP4.5 integrations of WACCM4, shown in Fig. 3a. Note that we here plot the trend, not the projection, as in the previous two figures; this is done to bring out the response to applied forcings. In Fig. 3a, one clearly sees a wetting trend at mid- to high latitudes poleward of $50^{\circ} \mathrm{S}$ and a drying trend equatorward of $50^{\circ} \mathrm{S}$ in the ensemble mean WACCM4 runs (thick red line). See also the good agreement between the individual ensemble members (thin red lines), which yields a statistically significant trend. Our WACCM4 results, also, are in good general agreement with the CMIP5 multimodel mean (blue curve), in both pattern and magnitude. And, as for the CMIP5, the latitudinal shift of the subtropical dry zone edge is statistically insignificant in WACCM4 (not shown).
Now we separate the hydrological cycle response into the one due to GHG increase and the one resulting from decreasing ODS (and the accompanying ozone recovery). In Fig. 3b we show the hydrological cycle response in the GHG $\uparrow$ experiment, where ODS are kept fixed. See how the trends in that case are noticeably different from the RCP4.5 case. For the GHG $\uparrow$ case, WACCM4 projects a moistening trend poleward of $55^{\circ} \mathrm{S}$ and a drying trend between $55^{\circ}$ and $35^{\circ} \mathrm{S}$, which results in a clear poleward shift of the hydrological cycle.

The difference between the RCP4.5 and GHG $\uparrow$ experiments can be seen in Fig. 3c. The response to decreasing ODS consists of a wetting trend in the midlatitudes between $60^{\circ}$ and $40^{\circ} \mathrm{S}$, and a drying trend in both the subtropics (between $40^{\circ}$ and $30^{\circ} \mathrm{S}$, though not statistically significant) and high latitudes (poleward of $\left.60^{\circ} \mathrm{S}\right)$. Note that, the magnitude of the response in the ODS $\downarrow$ case is similar in magnitude but opposite in sign to that of GHG $\uparrow$. This ODS $\downarrow$ response is also similar in pattern-but opposite in sign - to the one reported in Polvani et al. (2011, see their Fig. 11) and Kang et al. (2011, see their Fig. 3) for period stratospheric ozone depletion (roughly 1960-2000), when the ODS forcing is of opposite sign. In other seasons, the difference between the RCP4.5 and GHG $\uparrow$ experiments becomes negligible (not shown), as one would expect if ozone recovery is the primary forcing canceling the effect of increased GHG.

In summary then: the future response of the hydrological cycle in austral summer will depend very sensitively on both the GHG increase and stratospheric ozone recovery, which tend to offset each other. With the anticipated recovery of the Antarctic ozone hole, the wetting trend poleward of $60^{\circ} \mathrm{S}$ will be greatly reduced: this might have implications for the Southern Ocean (e.g., Durack et al. 2012) and the Antarctic continent. Furthermore, the significant poleward expansion of the subtropical dry zone associated with anthropogenic GHG increase will be also largely mitigated by the dry zone contraction due to stratospheric ozone recovery, leading to an insignificant position change of the hydrological cycle in the future. A more detailed understanding of the absence of shifts in the hydrological cycle in $\mathrm{SH}$ summer over the next several decades is discussed next.

\section{c. Dynamical mechanisms associated with hydrological cycle projections}

A quantitative evaluation of the mechanisms associated with the hydrological cycle response can be obtained by performing a complete moisture budget analysis, along the lines of Seager et al. (2007, 2010). The moisture budget analysis separates the response of $P-E$ into the contributions from the thermodynamic 
(a) P-E WACCM4: RCP4.5 2001-2065

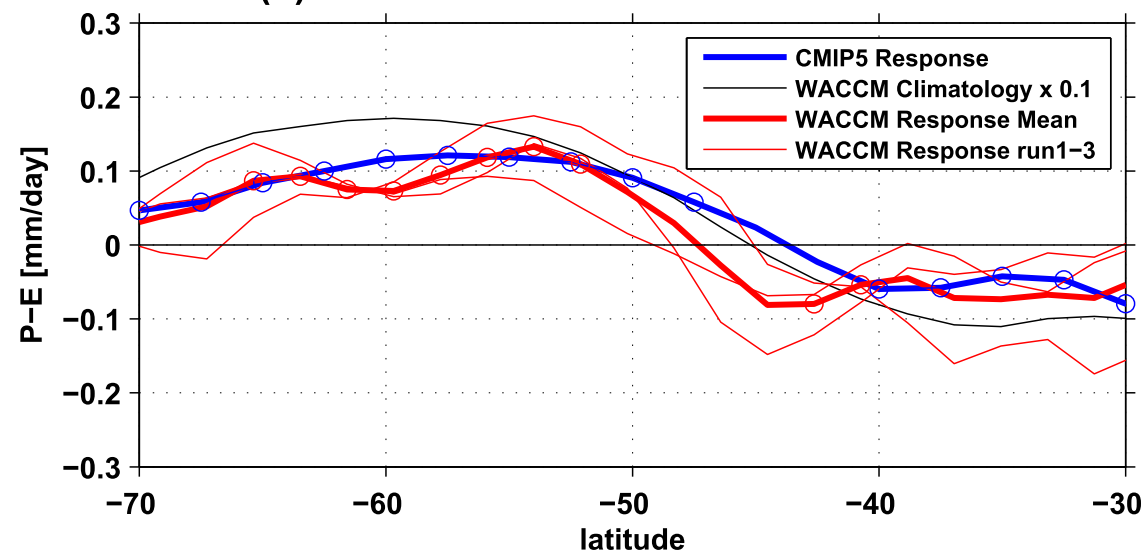

(b) P-E WACCM4: GHG $\uparrow$ 2001-2065

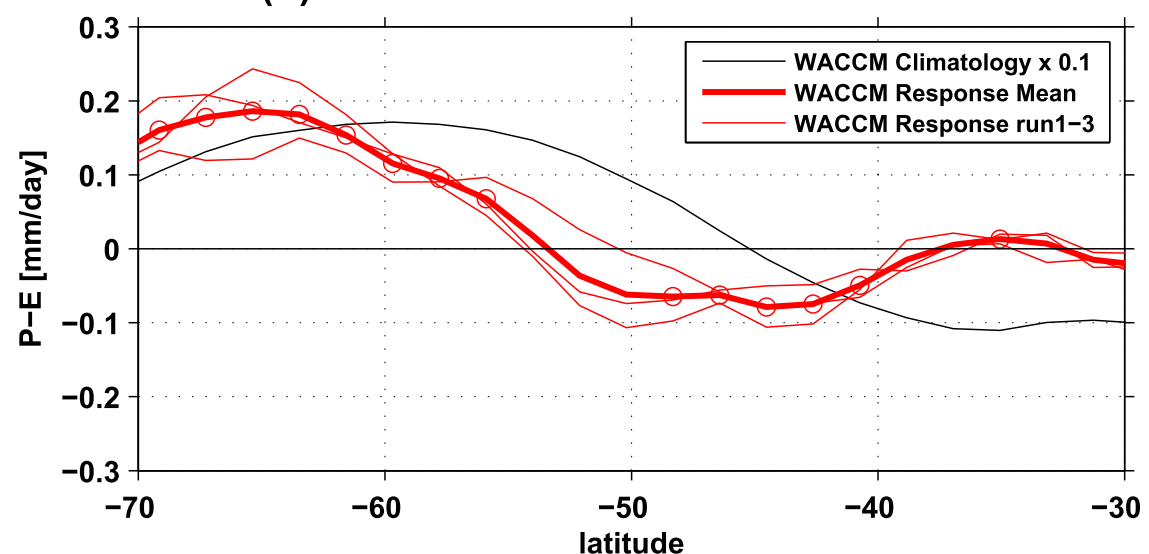

(c) P-E WACCM4: ODS $\downarrow$ 2001-2065

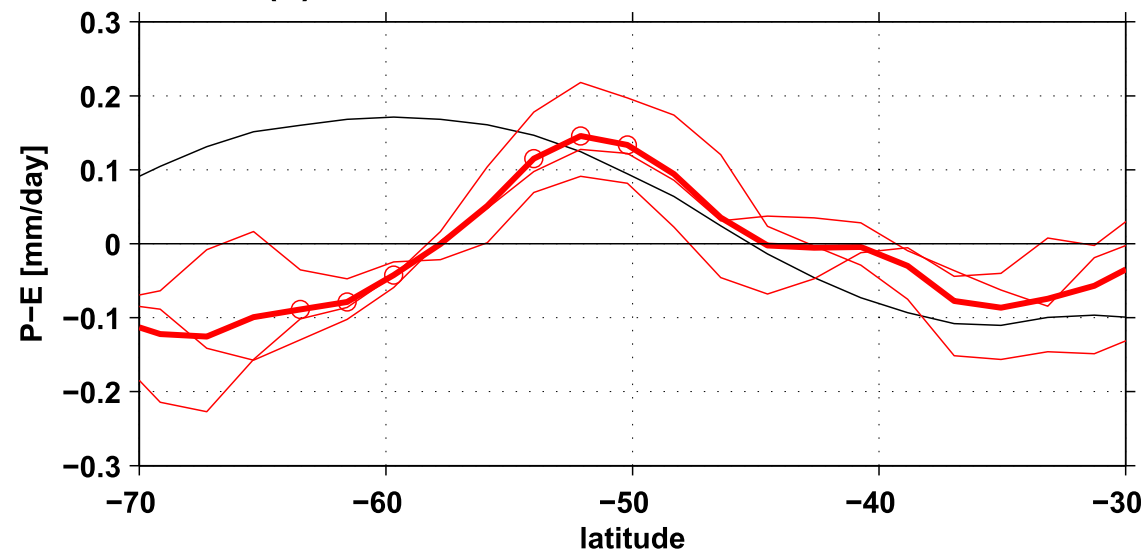

FIG. 3. The linear trend in zonal-mean $P-E$ in austral summer (DJF) during 2001-65 for (a) the RCP4.5 scenario, (b) the GHG $\uparrow$ experiment, and (c) the ODS $\downarrow$ experiment from the WACCM4 integrations. The thin black line shows the climatology of $P-E$ during 1981-2000 from the WACCM4 historical integrations, divided by a factor of 10 . The thick red line shows the linear trend of $P-E$ during 2001-65 as an average of three ensemble runs, and the thin red line shows the response from an individual run. The thick blue line shows the CMIP5 multimodel averages during 2001-65. Statistically significant responses, at the $90 \%$ level, are circled. 
(TH), the mean circulation dynamical (MCD), and the transient eddy (TE) components. It is written as

$$
\begin{aligned}
\delta\langle\overline{P-E}\rangle & \approx \delta \mathrm{TH}+\delta \mathrm{MCD}+\delta \mathrm{TE} \\
\delta \mathrm{TH} & =-\frac{1}{a g \rho_{w}} \frac{1}{\cos \phi} \frac{\partial}{\partial \phi}\left\langle\int_{0}^{p_{s}} \bar{v} \cdot \delta \bar{q} d p\right\rangle \cos \phi \\
\delta \mathrm{MCD} & =-\frac{1}{a g \rho_{w}} \frac{1}{\cos \phi} \frac{\partial}{\partial \phi}\left\langle\int_{0}^{p_{s}} \delta \bar{v} \cdot \bar{q} d p\right\rangle \cos \phi \\
\delta \mathrm{TE} & =-\frac{1}{a g \rho_{w}} \frac{1}{\cos \phi} \frac{\partial}{\partial \phi}\left\langle\int_{0}^{p_{s}} \delta \overline{v^{\prime} q^{\prime}} d p\right\rangle \cos \phi,
\end{aligned}
$$

where bars denote monthly averages, primes denote deviations from monthly averages, and brackets indicate zonal averages. The TH term identifies the change in zonal-mean specific humidity $(q)$, the MCD term tracks the response in zonal-mean circulation, and the TE term isolates the change in poleward moisture transport associated with transient eddies.

These individual components, as they contribute to the linear trends from 2001 to 2065 in the WACCM4 experiments, are shown in Fig. 4. To keep the figures readable, we only show the ensemble mean of three integrations in each panel. Note first that for all three cases (RCP4.5, GHG $\uparrow$, and ODS $\downarrow$ ), the sum of the TH, MCD, and TE terms, denoted by "moisture flux conv" (dashed-dotted red lines), reproduces very well the $P-E$ modeled trends (solid red lines). This confirms the usefulness of the analysis to clarify the underlying mechanism.

Let us start by considering the RCP 4.5 decomposition of the SH water cycle response, shown with Fig. 4a. The response of $P-E$ consists of an intensification in the middle and high latitudes-say, southward of $47^{\circ} \mathrm{S}-$ and a reduction at lower latitudes. From the budget analysis, it is clear that the transient eddy moisture flux (green line) is the largest of the three components. The mean circulation and thermodynamic terms also play some role.

In response to GHG increase, shown in Fig. 4b, the poleward shift of $P-E$ is again mostly due to a shift and intensification of transient eddy moisture flux. Interestingly, the thermodynamic component makes only a minor contribution to the intensification of the hydrological cycle, as does the mean circulation. The key role of transient eddies has already been noted, for example, by Seager et al. (2010).

In response to decreasing ODS, as seen in Fig. 4c, the change in $P-E$ is a near-mirror image of the one for the GHG $\uparrow$ case. Furthermore, the decline in $P-E$ at high latitudes in the ODS $\downarrow$ case is caused, equally, by changes in the mean circulation and transient eddies. In other words, the cancellation of future changes in the hydrological cycle is almost entirely dynamical, not thermodynamical, ${ }^{1}$ in origin.

Finally, we compute actual values for the latitudinal shift of the hydrological cycle in the WACCM4 integrations together with the specific contributions from the dynamics, including the expansion/contraction of the zonal-mean circulation and the poleward/equatorward shift of the moisture flux associated with transient eddies. Following $\mathrm{Lu}$ et al. (2010), we compute the latitudinal shift of a bell-shaped climate variable, $X$, using the expression

$$
\delta \phi=\frac{X_{r, \max }}{X_{p, \max }}\left(\delta X^{+}-\delta X^{-}\right)\left(\frac{d X_{r}^{-}}{d \phi}-\frac{d X_{r}^{+}}{d \phi}\right)^{-1},
$$

where $\delta \phi$ denotes the latitudinal shift; $r$ and $p$ denote the reference state and the perturbed state, respectively, the superscripts + and - denote the polar flank and the equatorward flank of the climate variable $X$, respectively; and $\delta X^{+}=X_{p}^{+}-X_{r}^{+}$and $\delta X^{-}=X_{p}^{-}-X_{r}^{-}$. A detailed derivation [Eq. (5)] can be found in Lu et al. (2010). This method measures the shift of the whole pattern of $X$ by making use of the dipolar structure of the response on the equatorward and poleward flanks, as well as the change in the magnitude of $X$.

We here compute the shift in three variables. The first, obviously, is $P-E$, for which we choose the latitudinal bands of + and - as $80^{\circ}-60^{\circ}$ and $60^{\circ}-40^{\circ} \mathrm{S}$, centered around $60^{\circ} \mathrm{S}$, where the climatological maximum is located. Second, we compute the shift of the zonal-mean streamfunction $\Psi$ maximum at $500 \mathrm{mb}$, with bands $70^{\circ}$ $50^{\circ}$ and $50^{\circ}-30^{\circ} \mathrm{S}$ chosen for the poleward and equatorward flanks, respectively, and centered around $50^{\circ} \mathrm{S}$, where $\Psi$ is maximal in the climatology. This variable denotes a shift in the Ferrel cell. The same parameters are chosen for the third variable: the eddy moisture flux $\left\langle\overline{v^{\prime} q^{\prime}}\right\rangle$ at $700 \mathrm{mb}$. The results are not sensitive to specific choices for the bands.

Figure 5 shows the latitudinal shift of the hydrological cycle, the zonal-mean circulation, and the transient eddy moisture flux in the WACCM4 integrations. Clearly, over the period 2001-65, there is no statistically significant shift of the hydrological cycle in the RCP4.5 experiment (black crosses). Furthermore, it is crystal clear that the absence of $P-E$ shifts is caused by the large

\footnotetext{
${ }^{1}$ The thoughtful reader may have noticed that the transient eddy term TE, as defined in Eq. (4), also involves changes in specific humity $\left(q^{\prime}\right)$, and hence it might be inappropriate to call this term a dynamical contribution. However, the changes in specific humidity resulting from stratospheric ozone forcing are usually very small, and it is through $v^{\prime}$ that the response to the forcing is realized.
} 
(a) P-E WACCM4: RCP4.5 2001-2065

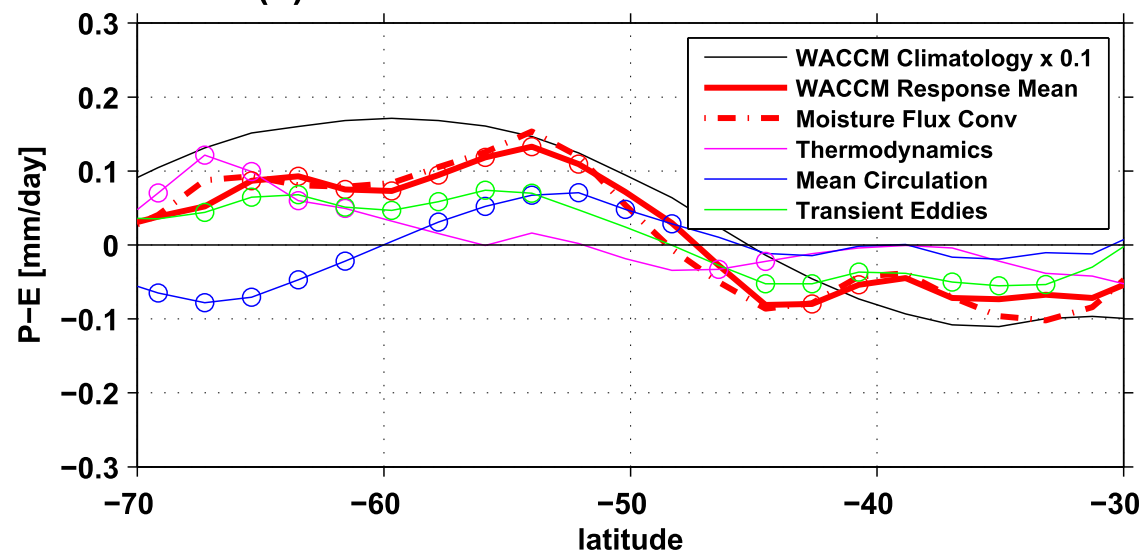

(b) P-E WACCM4: GHG $\uparrow$ 2001-2065

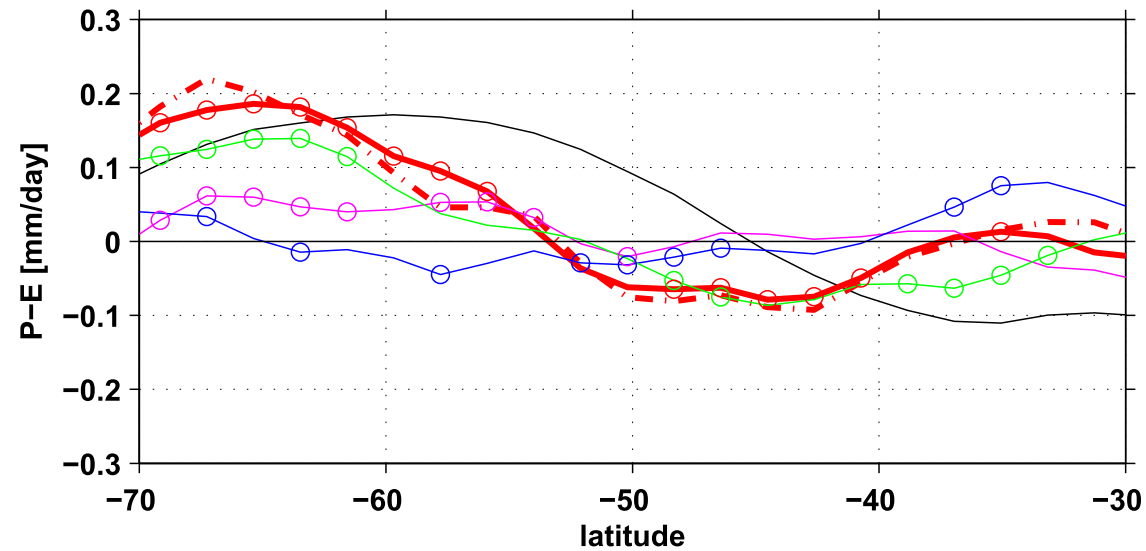

(c) P-E WACCM4: ODS $\downarrow$ 2001-2065

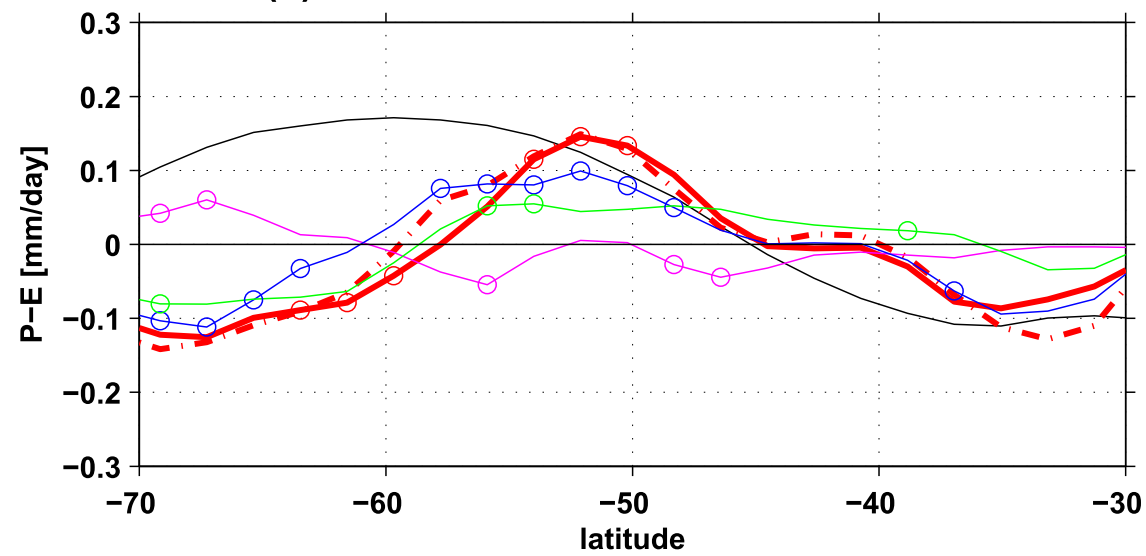

FIG. 4. The WACCM4 moisture budget analysis for the linear trend in zonal-mean $P-E$ in DJF for (a) the RCP4.5 scenario, (b) the GHG $\uparrow$ experiment, and (c) the ODS $\downarrow$ experiment. The 1981-2000 average of $P-E$, divided by a factor of 10, is plotted in a thin black line as a reference for climatology, and the linear trend of $P-E$ during 2001-65 is plotted in a thick red line. The sum of the TH (magenta), MCD (blue), and TE moisture flux convergence (green) components is denoted by "moisture flux conv" and is plotted in a thick dashed-dotted red line. 


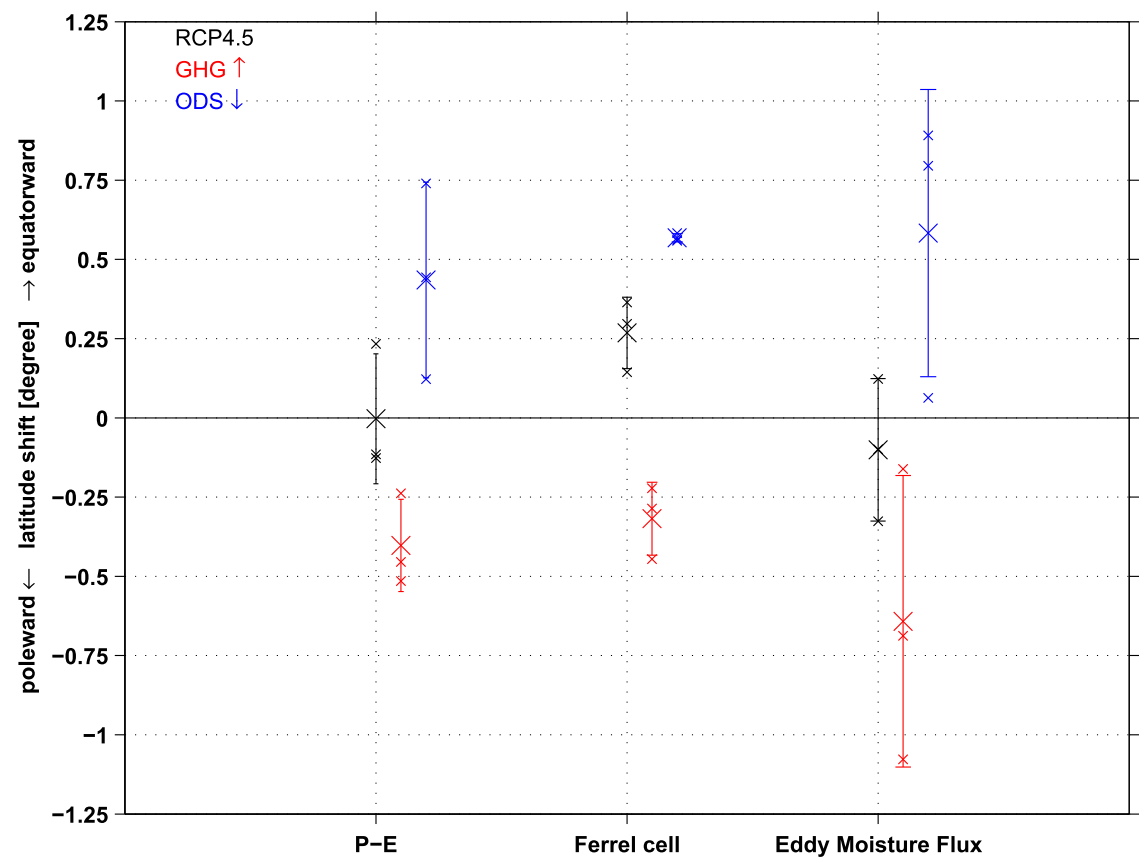

FIG. 5. The latitudinal shift of $P-E$, the Ferrel cell, and TE moisture flux in DJF during 2001-65. Black indicates the RCP4.5 scenario, red the GHG $\uparrow$ experiment, and blue the ODS $\downarrow$ experiment. Large crosses show ensemble averages, small crosses show individual ensemble members, and bars show one standard deviation for each ensemble.

cancellation between increasing greenhouse gases (red) - producing a poleward shift of about $0.5^{\circ}$ in ensemble average - and the comparable equatorward shift due to decreasing ODS (and the accompanying recovery of stratospheric ozone).

In terms of mechanisms, this cancellation in the shift of the hydrological cycle comes, largely, from changes in the mean circulation and transient eddies, not the thermodynamics. While the Ferrel cell tends to move poleward in response to greenhouse warming (about $0.3^{\circ}$ poleward in ensemble mean), the recovery of ozone shifts the zonal-mean circulation in the midlatitudes equatorward by about $0.5^{\circ}$ latitude in ensemble average. In the WACCM4 RCP4.5 simulations, the Ferrel cell moves slightly equatorward, due to the shift on the polar flank but we find no shift on the equatorward flank (which corresponds to the southern edge of the Hadley cell, not shown). The near cancellation is also seen in the moisture transport associated with the transient eddies despite a larger ensemble spread for the RCP4.5 experiment.

\section{Conclusions}

We have shown that there exists a marked difference between the short- and long-term predictions of changes in the zonal-mean precipitation, in the SH summer subtropics, in the CMIP5 models. In a nutshell, the robust projections of midlatitude shifts that have been reported in the literature are not seen until the very end of the twenty-first century and, for the next 50 years, no significant zonal-mean trends are projected in that season in the SH.

Confirming earlier studies reviewed in the introduction, and with the help of new single-forcing integrations with WACCM4, a stratosphere-resolving model with interactive ozone chemistry, we have demonstrated that the decreased concentration of ODS (resulting in the closing of the ozone hole in the next several decades) is the key anthropogenic forcing that will cancel the GHG-induced poleward shift in the water cycle. In essence, therefore, the Montreal Protocol will result in a substantial mitigation of climate change, in the sense of a multidecadal long delay in the emergence of the effects of GHG, in SH summer.

One might be tempted to argue that the climate impacts of the Montreal Protocol will be relatively small, as they will be confined to a single season. Such an argument, however, is simplistic. First, recall that summer is the rainy season in most parts of the Southern Hemisphere, notably South America, South Africa, and eastern Australia. Second, note that while the findings here are uniquely focused on the zonal mean, there is reason to believe that the impact of the Montreal Protocol will be keenly felt in specific regions. 
(a) Australia GHG $\uparrow$

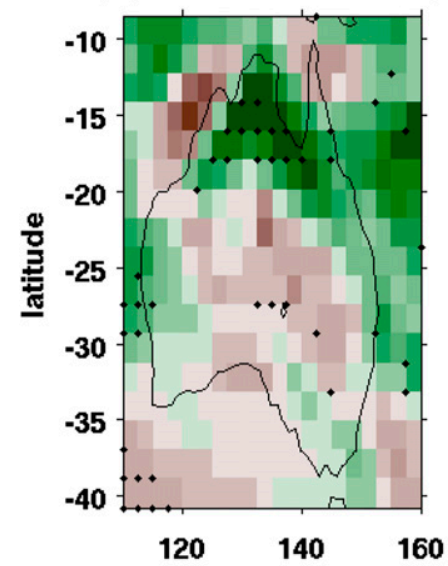

(e) Australia ODS $\downarrow$

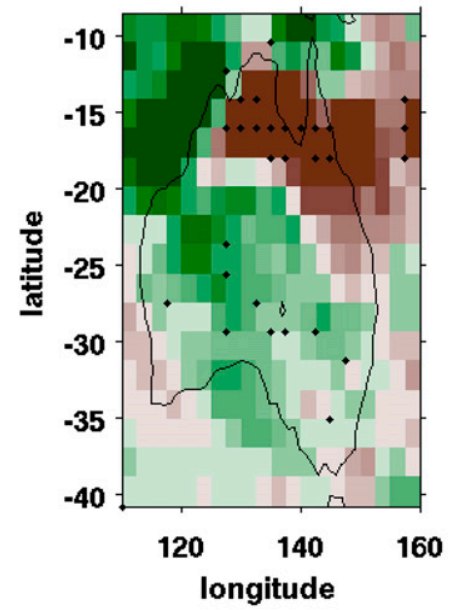

(b) SESA GHG $\uparrow$

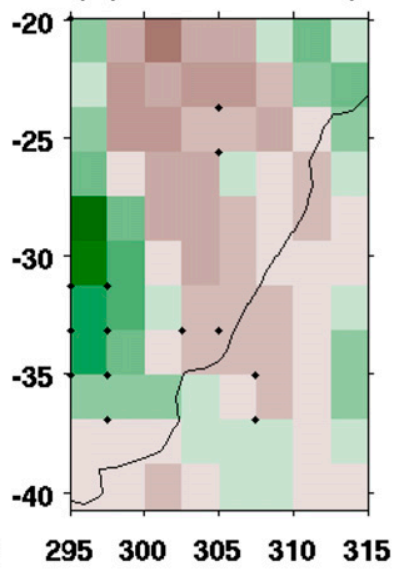

(c) New Zealand GHG $\uparrow$ (d) Tasmania GHG $\uparrow$

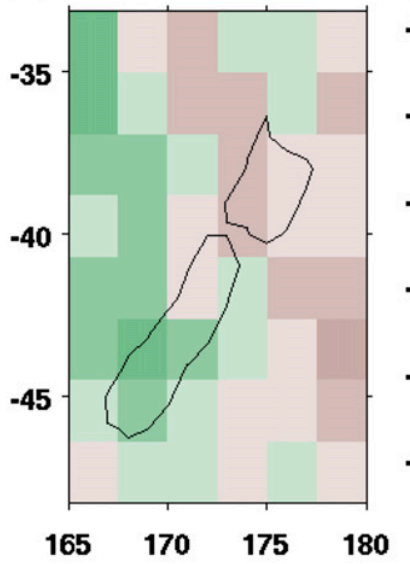

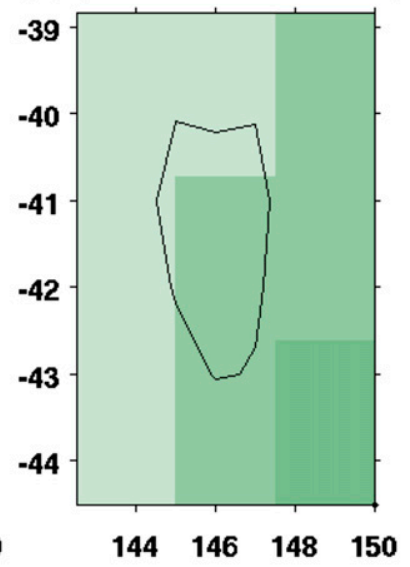

(f) SESA ODS $\downarrow$

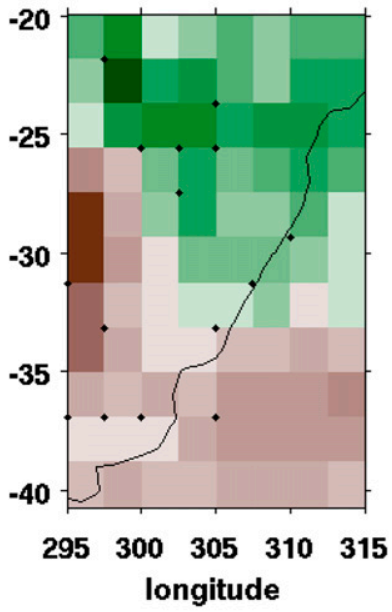

(g) New Zealand ODS $\downarrow$ (h) Tasmania ODS $\downarrow$

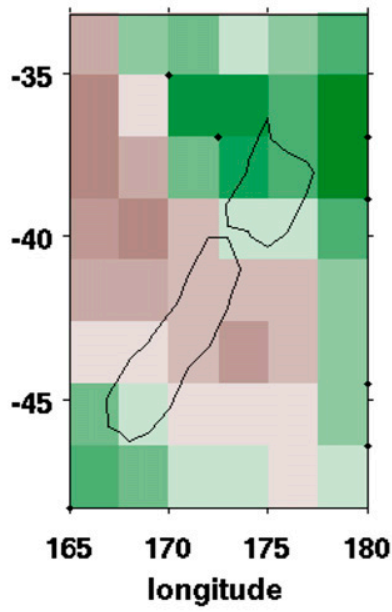

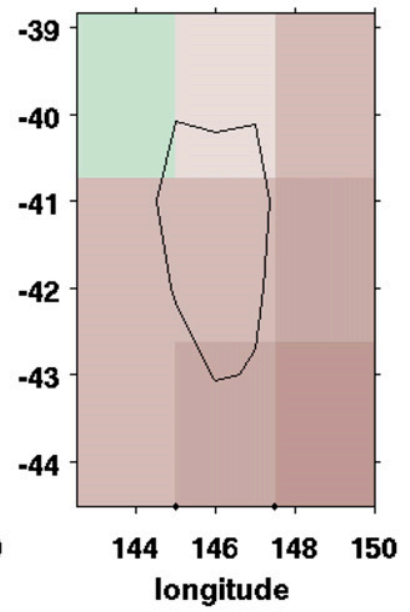

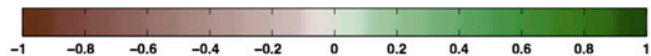

FIG. 6. The linear trend in $P-E\left(\right.$ mm day $^{-1}$ ) in DJF during 2001-65 in (a),(e) Australia, (b),(f) SESA, (c),(g) New Zealand, and (d),(h) Tasmania in the (top) GHG $\uparrow$ and (bottom) ODS $\downarrow$ experiments. Statistically significant responses, at the $90 \%$ level, are dotted.

A clear example is offered by the region known as southeastern South America (SESA), which has experienced the world's largest increase in precipitation in the late twentieth century. As shown in Gonzalez et al. (2014), the formation of the ozone hole in the late decades of the twentieth century has been a key driver of those observed precipitation increases. Hence, as the ozone hole closes in the coming decades, there is every reason to expect that the recent precipitation increases will be greatly reduced, and possibly reversed.

Keeping in mind that we only have three ensemble members at our disposal, and that the version of WACCM used here has a relatively coarse horizontal resolution $\left(1.9^{\circ}\right.$ in latitude and $2.5^{\circ}$ in longitude), we nonetheless attempt to offer a glimpse of how on regional scales the recovery of stratospheric ozone in the coming decades might offset the impact of increasing greenhouse gases on the hydrological cycle. In Fig. 6, we plot the 2001-65 December-February (DJF) trends in $P-E$, for four regions of interest (Australia, SESA, New Zealand, and Tasmania): the top row shows the response to increasing GHG and the bottom row shows the response to decreasing ODS. While there is little statistical significance beyond some parts of Australia and possibly SESA, we draw the reader's attention to a simple fact: the colors in the top and bottom rows are clearly reversed, indicating that the trends associated with ODS and GHG forcings are basically opposite in sign-and this happens in all four regions. Of course this is merely impressionistic, and any conclusions from a single model need to be taken with extreme cautionthat said, Fig. 6 does suggest that the ODS/GHG 
cancellation might actually be observable in some populated areas of the Southern Hemisphere, although we leave a thorough study of any given region for future papers.

Finally, a note about internal variability: As the hydrological cycle in SH summer will be driven, in the short term, by two large yet opposing anthropogenic forcings (increasing GHG and decreasing ODS), the role of internal climate variability will be larger than what it otherwise would be. While the CMIP5 multimodel mean shows a nonexistent trend, it is entirely possible that either positive or negative trends will actually occur. Hence, while the Montreal Protocol might be said to result in a mitigation of the effect of increasing GHG in the near future, it also renders climate projections more uncertain than they would otherwise be.

Acknowledgments. The authors acknowledge the help of Dr. Haibo Liu for obtaining the CMIP5 data and thank Dr. Jack Scheff for the several useful comments on an earlier draft of the paper. The authors acknowledge the World Climate Research Programme's Working Group on Coupled Modelling, which is responsible for CMIP, and we thank the climate modeling groups (listed in Table 1 of this paper) for producing and making available their model output. For CMIP the U.S. Department of Energy's Program for Climate Model Diagnosis and Intercomparison provides coordinating support and led development of software infrastructure in partnership with the Global Organization for Earth System Science Portals. YW is supported by a start-up fund from the Department of Earth, Atmospheric, and Planetary Sciences at Purdue University. LMP is supported by a grant from the U.S. National Science Foundation.

\section{REFERENCES}

Arblaster, J. M., G. A. Meehl, and D. J. Karoly, 2011: Future climate change in the Southern Hemisphere: Competing effects of ozone and greenhouse gases. Geophys. Res. Lett., 38, L02701, doi:10.1029/2010GL045384.

Barnes, E. A., N. W. Barnes, and L. M. Polvani, 2014: Delayed Southern Hemisphere climate change induced by stratospheric ozone recovery, as projected by the CMIP5 models. J. Climate, 27, 852-867, doi:10.1175/JCLI-D-13-00246.1.

Charlton-Perez, A. J., and Coauthors, 2013: On the lack of stratospheric dynamical variability in low-top versions of the CMIP5 models. J. Geophys. Res. Atmos., 118, 2494-2505, doi:10.1002/jgrd.50125.

Durack, P. J., S. E. Wijffels, and R. J. Matear, 2012: Ocean salinities reveal strong global water cycle intensification during 1950 to 2000. Science, 336, 455-458, doi:10.1126/science.1212222.

Eyring, V., and Coauthors, 2013: Long-term ozone changes and associated climate impacts in CMIP5 simulations. J. Geophys. Res. Atmos., 118, 5029-5060, doi:10.1002/jgrd.50316.
Gonzalez, P., L. Polvani, R. Seager, and G. Correa, 2014: Stratospheric ozone depletion: A key driver of recent precipitation trends in South Eastern South America. Climate Dyn., 42, 1775-1792, doi:10.1007/s00382-013-1777-x.

Held, I. M., and B. J. Soden, 2006: Robust responses of the hydrological cycle to global warming. J. Climate, 19, 5686-5699, doi:10.1175/JCLI3990.1.

Kang, S., L. M. Polvani, J. C. Fyfe, and M. Sigmond, 2011: Impact of polar ozone depletion on subtropical precipitation. Science, 332, 951-954, doi:10.1126/science.1202131.

Lu, J., G. A. Vecchi, and T. Reichler, 2007: Expansion of the Hadley cell under global warming. Geophys. Res. Lett., 34, L06805, doi:10.1029/2006GL028443.

— G. Chen, and D. M. W. Frierson, 2010: The position of the midlatitude storm track and eddy-driven westerlies in aquaplanet AGCMs. J. Atmos. Sci., 67, 3984-4000, doi:10.1175/ 2010JAS3477.1.

Marsh, D. R., M. J. Mills, D. E. Kinnison, J.-F. Lamarque, N. Calvo, and L. M. Polvani, 2013: Climate change from 1850 to 2005 simulated in CESM1(WACCM). J. Climate, 26, 73727391, doi:10.1175/JCLI-D-12-00558.1.

McLandress, C., T. G. Shepherd, J. F. Scinocca, D. A. Plummer, M. Sigmond, A. I. Jonsson, and M. C. Reader, 2011: Separating the dynamical effects of climate change and ozone depletion. Part II: Southern Hemisphere troposphere. J. Climate, 24, 1850-1868, doi:10.1175/2010JCLI3958.1.

Meinshausen, M., and Coauthors, 2011: The RCP greenhouse gas concentrations and their extensions from 1765 to 2300 . Climatic Change, 109, 213-241, doi:10.1007/s10584-011-0156-z.

Perlwitz, J., S. Pawson, R. L. Fogt, J. E. Nielsen, and W. D. Neff, 2008: Impact of stratospheric ozone hole recovery on Antarctic climate. Geophys. Res. Lett., 35, L08714, doi:10.1029/ 2008 GL033317.

Polvani, L. M., M. Previdi, and C. Deser, 2011: Large cancellation, due to ozone recovery, of future Southern Hemisphere atmospheric circulation trends. Geophys. Res. Lett., 38, L04707, doi:10.1029/2011GL046712.

Scheff, J., and D. Frierson, 2012a: Robust future precipitation declines in CMIP5 largely reflect the poleward expansion of model subtropical dry zones. Geophys. Res. Lett., 39, L18704, doi:10.1029/2012GL052910.

$\longrightarrow$, and —, 2012b: Twenty-first-century multimodel subtropical precipitation declines are mostly midlatitude shifts. J. Climate, 25, 4330-4347, doi:10.1175/JCLI-D-11-00393.1.

Seager, R., and Coauthors, 2007: Model projections of an imminent transition to a more arid climate in southwestern North America. Science, 316, 1181-1184, doi:10.1126/science.1139601.

_ N. Naik, and G. A. Vecchi, 2010: Thermodynamic and dynamic mechanisms for large-scale changes in the hydrological cycle in response to global warming. J. Climate, 23, 4651-4668, doi:10.1175/2010JCLI3655.1.

Smith, K. M., L. M. Polvani, and D. R. Marsh, 2012: Mitigation of 21st century Antarctic sea ice loss by stratospheric ozone recovery. Geophys. Res. Lett., 39, L20701, doi:10.1029/2012GL053325.

Son, S.-W., N. Tandon, L. M. Polvani, and D. Waugh, 2009: Ozone hole and Southern Hemisphere climate change. Geophys. Res. Lett., 35, L15705, doi:10.1029/2009GL038671.

Taylor, K. E., R. J. Stouffer, and G. A. Meehl, 2012: An overview of CMIP5 and the experiment design. Bull. Amer. Meteor. Soc., 93, 485-498, doi:10.1175/BAMS-D-11-00094.1.

Yin, J. H., 2005: A consistent poleward shift of the storm tracks in simulations of 21st century climate. Geophys. Res. Lett., 32, L18701, doi:10.1029/2005GL023684. 